\title{
Variação sazonal do fluxo de calor no solo dentro de um manguezal tropical
}

\author{
$\overline{\text { Marcos A. L Moura' } \& \text { Carlos A. S. Querino }}$
}

\begin{abstract}
RESUMO
Os manguezais são ecossistemas de grande importância em virtude da sua biodiversidade, embora ainda pouco estudados. 0 fluxo de calor no solo (FCS) é uma propriedade que interfere no microclima de um ecossistema e depende de vários fatores. Um estudo experimental foi realizado em um manguezal no município de Marechal Deodoro, Alagoas, no período de outubro/2004 a outubro/2005, com o objetivo de caracterizar a variação sazonal do FCS; para isto, uma estação meteorológica automática foi montada em uma torre micrometeorológica para registrar diferentes elementos do tempo e clima, de forma contínua. Especificamente, para medição do FCS a $10 \mathrm{~cm}$ de profundidade utilizou-se uma bateria de três fluxímetros modelo HFT3 (Campbell Scientific, EUA) no sentido de que a interferência da não uniformidade do solo nas medições fosse minimizada. 0 s resultados obtidos demonstraram influência da radiação solar, precipitação e da maré sobre a variação diária e sazonal do FCS, além de grande diferença de amplitude diária do FCS entre oS períodos chuvoso $\left(9 \mathrm{~W} \mathrm{~m}^{-2}\right)$ e seco $\left(36 \mathrm{~W} \mathrm{~m}^{-2}\right)$.
\end{abstract}

Palavraschave: complexo lagunar, solo, maré, radiação solar

\section{Seazonal variation of soil heat flux within tropical mangrove}

\begin{abstract}
Mangrove swamps are highly important ecosystems due to their biodiversity, but they still are little studied. Soil heat fluxes (SHF) is one of the proprieties that interfere in the ecosystem microclimate and depends on lots of factors. An experimental study was carried out in a mangrove forest in the Marechal Deodoro city, in the State of Alagoas, from 0 ctober/2004 to 0 ctober/2005, with the aim of describing the SHF seasonal variation. To this end, an automatic weather station was assembled in a micrometeorological tower to register the data continuously. To measure SHF in $10 \mathrm{~cm}$ depth one battery with three (3) fluximeter model HFT3 (Campbell Scientific, EUA) was used so that the soil uniformity interference in the measurements was reduced. The obtained results showed influence of solar radiation, rainfall and tidal wave in the daily and seasonal SHF variation. A large SHF amplitude daily difference occurred between the wet $\left(9 \mathrm{~W} \mathrm{~m}^{-2}\right)$ and dry $\left(36 \mathrm{~W} \mathrm{~m}^{-2}\right)$ season.
\end{abstract}

Key words lagunar complex, soil, tide, solar radiation

\footnotetext{
1 Instituto de Ciências Atmosféricas/U FAL. BR 104, Norte, Km 97, Cidade U niversitária, CEP 57072-970, Maceió, AL. Fone: (82) 3214-1370. E-mail: malm@ccen.ufal.br

2 Instituto de Agricultura e Ambiente, Campus Vale do Rio Madeira/UFAM, Rua 29 de Agosto, s/n, Centro, CEP 69800-000, Humaitá, AM. Fone: (97) $3373-1180$. E-mail: querinocarlos@hotmail.com
} 


\section{INTRODUÇÃO}

Manguezais são componentes significativos dos ecossistemas tropicais (Vance et al., 1990), que se desenvolvem em zonas litorâneas associadas a cursos d’água, em áreas encharcadas, salobras e calmas, com influência das marés, porém não atingidos pela ação direta das ondas. Geralmente, são sistemas jovens que, seguindo a dinâmica das marés nas áreas em que se localizam, produzem a modificação na topografia desses terrenos, resultando em uma sequência de recuos e avanços da cobertura vegetal (Schaeffer-Novelli, 2002).

Se não bastasse a sua importância para o ser humano, é merecedor de destaque o papel dos manguezais como estabilizadores ambientais, funcionando como barreiras naturais contra impactos permanentes de inundações catastróficas, além da erosão eólica, causada por furacões e ciclones, e hídrica, pela ação das ondas (Vanucci, 1999). Os manguezais existem em praticamente todos os continentes e estão nas regiões tropicais e subtropicais, alcançando maiores extensões nos estuários ou locais de geografia plana onde a maré tem maior fluxo; no Brasil, sua área é de cerca de $25.000 \mathrm{~km}^{2}$, segundo Schaeffer-Novelli (1995).

Os fatores ambientais que controlam e influenciam a estrutura e a produtividade das florestas de manguezais variam no tempo e no espaço (Day Jr. et al., 1996) e dentre eles se destacam: hidrologia, entrada de nutrientes, salinidade e tipo do solo (Lugo et al., 1988). Fatores climáticos, tais como a radiação solar, o comprimento do dia, a temperatura do ar e do solo, a precipitação e a evapotranspiração potencial, assim como sua variabilidade sazonal, são imprescindíveis nos danos à produção líquida primária e crescimento de florestas de manguezais no mundo (Clough, 1992).

Apesar da magnitude do estudo dos manguezais sob vários aspectos da ciência, pouco se conhece a respeito dos processos de troca de massa, energia, "momentum” e parâmetros bióticos e abióticos, dentro e acima do dossel. A superfície do solo é um dos componentes determinantes do microclima da planta (Sediyama \& Prates, 1986) e serve não só como suporte para as plantas mas, também, para o meio, através do qual a água e os nutrientes são transferidos para o sistema radicular; por outro lado o solo funciona, fisicamente, como principal mecanismo de armazenamento de energia. Segundo Firme (2003), os solos dos manguezais são diferenciados de solos agricultáveis, haja vista que se percebe esta diferença ao se comparar valores médios de alguns cátions trocáveis desses solos com as tabelas que existem na literatura sendo que, na maioria dos casos, os solos dos mangues ultrapassam os limites encontrados.

A transferência de calor no solo do manguezal é originada através de uma complexa combinação de processos condutivo e convectivo intraporoso (Silans et al., 1996). Não só o fluxo de calor no solo, mas também a sua temperatura em área de manguezal sofrem profundas modificações durante o ano devido ao aporte de materiais transportados do mar para o interior do manguezal e vice-versa; além disso, o influxo de água salina no solo é constante através dos canais de entrada, o que torna o balanço anual dessas variáveis relativamente complexo (Ribeiro et al., 2007). O fluxo de ca- lor no solo é um componente necessário do balanço de energia à superfície, capaz de justificar o armazenamento e a transferência de calor dentro do solo e, ainda, as trocas entre o solo e a atmosfera.

A região de manguezais é pouco estudada sob o aspecto de variáveis micrometeorológicas, trazendo sempre dúvidas quanto ao comportamento dessas variáveis em razão do desconhecimento da interação entre o ecossistema de manguezal e os processos físicos na interface solo-atmosfera, ficando difícil identificar condições propícias à sustentabilidade do equilíbrio microclimático nos manguezais; então, o objetivo do presente trabalho é caracterizar a dinâmica sazonal do fluxo de calor no solo de um manguezal tropical, o que constituirá, sem dúvida, valiosa ferramenta, no que concerne à resposta desse ecossistema às condições ambientais existentes e aos processos de alteração do meio ambiente auxiliando, assim, nos estudos e ações que objetivarem a conservação desse ecossistema.

\section{MATERIAL E MÉTODOS}

O estudo foi realizado com a coleta de dados durante o período de outubro/2004 a outubro/2005, em um sítio experimental localizado no Complexo Estuarino Lagunar Mundaú-Mangaba, pertencente à Área de Proteção Ambiental (APA) da Ilha de Santa Rita (Figura 1), que abrange, concomitantemente, 7 municípios do Estado de Alagoas, Brasil: cerca de $44 \%$ da respectiva área estão degradados, segundo o IMA (1993); acredita-se, entretanto, que atualmente a taxa de degradação seja maior apesar de não se contar com dados atualizados divulgados pelos órgãos responsáveis.

O referido sítio ( $9^{\circ} 42^{\prime} 18^{\prime}$ S e $35^{\circ} 48^{\prime} 32^{\prime}$ W) apresenta vegetação nativa, mais especificamente floresta de manguezal com altura média do dossel de $10 \mathrm{~m}$, dotado de uma área de aproximadamente $416 \mathrm{mil} \mathrm{m} \mathrm{m}^{2}$ que, segundo Calado \& Sousa (2003) tem uma vegetação arbórea constituída de poucas espécies que apresentam adaptações estruturais e fisiológicas

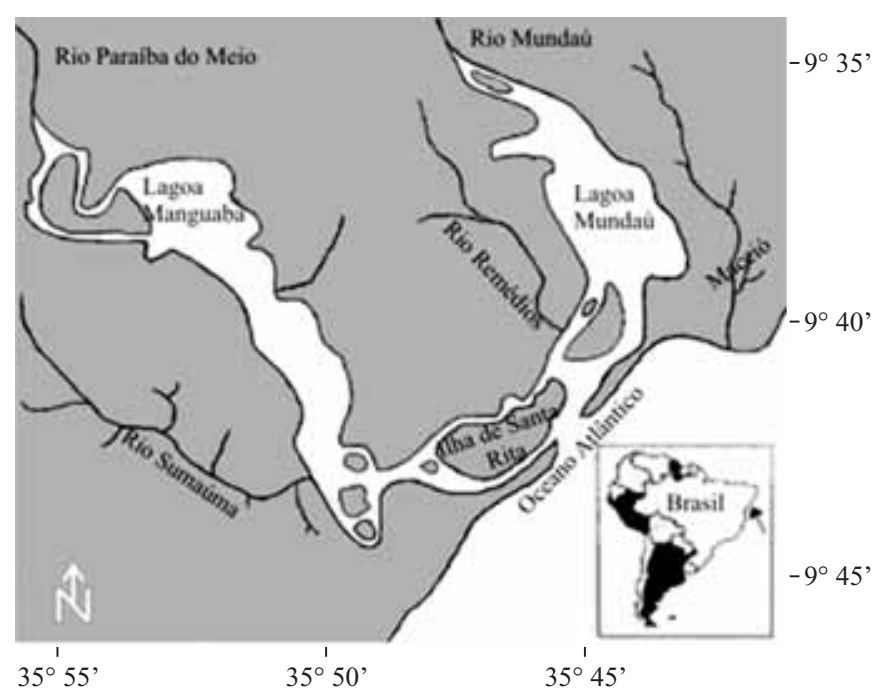

Figura 1. Localização geográfica do Complexo Estuarino Lagunar M undaúMangaba, Alagoas, Brasil 
necessárias às condições oferecidas por este ambiente e composta de três tipos predominantes: Avicennia germinans L., vulgarmente chamada mangue preto; a Rhizophora mangle L., também conhecida como gaitera ou mangue vermelho, e a Laguncularia racemosa C. F. Gaertn, acatada como mangue branco ou tinteira.

As marés na entrada do complexo estuarino são predominantemente semidiurnas com altura média de $2 \mathrm{~m}$, conforme pode se observa nos dados relativos à maré, no porto de Maceió, no site da Diretoria de Hidrografia e Navegação (DHN, 2007). A floresta de mangue é inundada duas vezes ao dia pela maré, através dos canais com altura máxima de $0,50 \mathrm{~m}$, onde estava instalada a torre meteorológica cuja amplitude, segundo Lima (1990), tem retardamento aproximado de 1 h e meia em relação à subida e vazante da maré entre o interior e a entrada do complexo, sendo ainda influenciada pela pluviometria e morfologia lagunar. O solo do manguezal é pobre em oxigênio e rico em matéria orgânica, incompletamente decomposta. O fluxo e o refluxo das marés promovem a circulação dos nutrientes e alimentos, além da remoção dos produtos inaproveitáveis do metabolismo dos organismos. A mistura das águas nos estuários promove processos de floculação, permitindo a deposição de frações arenosas finas que constituem o sedimento lamoso. Lamberti (1969) verificou que nos períodos com pluviosidade variável as concentrações dos componentes físicos e químicos do solo não sofrem oscilações importantes apesar de, segundo Teixeira \& Sá (1998), a salinidade média variar entre 0,6\%。 no período chuvoso até $19,7 \%$ no período seco. As características físicas do solo do mangue e que foram realizadas em agosto/2005 pelo Departamento de Solos, Engenharia e Economia Rural da Universidade Federal de Alagoas, estão descritas na Tabela 1.

Tabela 1. Anal ise físico-química e classificação do solo quanto à sua textura para área de mangue natural (Illha de Santa Rita, Maceió, Alagoas, 2005)

\begin{tabular}{lccc}
\hline \multirow{2}{*}{ Determinações } & \multicolumn{3}{c}{ Profundidades (cm) } \\
\cline { 2 - 4 } pH & $\mathbf{0 - 1 0}$ & $\mathbf{1 0 - 2 0}$ & $\mathbf{2 0 - 3 0}$ \\
Mat. org. total (\%) & 6,1 & - & - \\
Areia grossa (\%) & 3,31 & - & - \\
Areia fina (\%) & 33 & 36 & 36 \\
Silte (\%) & 51 & 32 & 33 \\
Argila (\%) & 12 & 28 & 27 \\
Silte/Argila & 4 & 4 & 4 \\
Densidade do solo (g cm $\left.{ }^{-3}\right)$ & 3,00 & 7,00 & 6,75 \\
Porosidade total (\%) & 1,17 & 1,14 & 1,11 \\
Classificação textural (SBCS) & Areia Franca & Franco Arenosa Franco Arenosa \\
\hline
\end{tabular}

O clima do complexo Mundaú-Manguaba foi descrito por Cabús (2002) como sendo tropical, semiúmido com estações chuvosa (maio a agosto), responsável por aproximadamente $60 \%$ do total médio anual de precipitação, de 2.167,7 mm, e seca (dezembro a março), bem definidas (classificação Köppen Am), sendo os outros meses considerados de transição. A média anual da temperatura do ar é $25,5^{\circ} \mathrm{C}$ com variação média anual de $3,4^{\circ} \mathrm{C}$. A umidade relativa anual média é 78,3\% com máximo em maio (82,6\%) e a mínima em novembro (74,7\%). Durante a estação chuvosa o vento sopra, predominantemente, de sudeste (SE) e de leste (E) na estação seca, com velocidade média (obtida a $10 \mathrm{~m}$ ) de $6 \mathrm{~m} \mathrm{~s}^{-1}$ em ambas as estações; esta é a principal diferença climática entre as estações seca e chuvosa. No interior do mangue foi erguida uma torre de $14 \mathrm{~m}$, na qual se instalaram vários sensores para monitorar diferentes variáveis (radiação solar global, difusa e refletida, temperatura e umidade do ar, vento, etc). Para eliminar possíveis efeitos devidos ao sombreamento da torre sobre as medidas do fluxo de calor no solo, os sensores foram posicionados em relação à torre, a uma distância de 2,5 m.

Durante todo o período experimental foram coletados, permanentemente, dados do fluxo de calor no solo; para isto se utilizou uma bateria com três fluxímetros do modelo HFT3 (Campbell Scientific, Inc, EUA), os quais foram instalados a $0,10 \mathrm{~m}$ de profundidade. O objetivo de se usar uma bateria é no sentido de que a interferência da não uniformidade do solo nas medições fosse minimizada; todos os fluxímetros estavam conectados a um Datalogger 21X (Campbell Scientific, EUA) que, por sua vez, tinha um Módulo de Armazenamento de Dados do tipo SM716 (Campbell Scientific, EUA), no qual eram armazenados os dados em média de 5 min após medições realizadas a cada 10 s e descarregados posteriormente, em laboratório, para consequente tratamento e utilização.

Também se utilizou a equação da amplitude para estimar a difusividade térmica do solo $\left(\mathrm{k}_{1}\right)$, conforme descrito por Verhoef et al. (1996):

$$
\mathrm{k}_{1}=\frac{\pi(\Delta \mathrm{Z})^{2}}{\mathrm{p} \ln ^{2}\left(\mathrm{~A}_{1} / \mathrm{A}_{2}\right)}
$$

donde p é o período da onda de temperatura (= 1 dia), $\mathrm{A}_{1} \mathrm{e}$ $A_{2}$ são as amplitudes nas profundidades $Z_{1}$ e $Z_{2}$ e $\Delta z$ é igual a $\mathrm{Z}_{2}-\mathrm{Z}_{1}$.

\section{RESULTADOS E DISCUSSÃO}

O fluxo de calor do solo (FCS) é um dos componentes do balanço de energia terrestre que interessam a todos os estudiosos ligados ao clima; contudo, sua determinação é difícil (Kimball et al., 1976) e imprecisa (Liebethal et al., 2005). O fluxo de calor no solo ocorre em razão do processo de condução no qual, por movimento molecular, é transmitido a moléculas adjacentes, decrescentemente. Esta transmissão acontece quando o sistema não está em equilíbrio térmico pois, quer durante o dia ou à noite, ocorrem trocas de calor entre a superfície do solo e a atmosfera, tanto por condução quanto por irradiação e há intercâmbio de calor entre a superfície do solo e a atmosfera nos processos de evaporação e condensação da água.

Os dados do FCS observados demonstraram algumas características importantes no seu ciclo anual no manguezal, incluindo a quantificação do range sazonal do FCS, quando então se percebe, na Figura 2A, uma evidente diferença 
entre as épocas seca (nov-dez-jan-fev) e chuvosa (mai-junjul-ago) regionais, apesar dos valores máximos médios sempre se apresentarem entre 12 e $14 \mathrm{~h}$, independentemente da estação climática, como claro sinal da sua dependência da radiação solar global incidente (Rg); no entanto, quando se confronta com a Figura 2B se observa que o FCS é uma função da radiação solar incidente à superfície, principalmente no período diurno; salienta-se, porém, que no período chuvoso a amplitude diária média corresponde a $9 \mathrm{~W} \mathrm{~m}^{-2}$ enquanto no período seco foi de $36 \mathrm{~W} \mathrm{~m}^{-2}$, o que evidencia resultado da atenuação do Rg através das camadas mais elevadas do dossel, nas quais a quantidade de radiação que chega à superfície é consideravelmente inferior àquela incidente no topo do dossel vegetativo e, portanto, a transferência de calor no solo é menos elevada tanto que, segundo Querino (2006), nos meses compreendidos entre maio e agosto, quando o Sol se encontra astronomicamente posicionado no hemisfério norte, ocorrem as maiores atenuações da Rg na superfície do manguezal por influência da maior inclinação dos raios solares, em que apenas aproximadamente $15 \%$ da Rg incidente no topo do dossel vegetativo atingem a superfície.

Quando se analisam meses específicos das épocas seca e chuvosa (Figuras 2C e 3) pode-se perceber mais claramente a influência conjunta da radiação solar incidente no chão do manguezal e da precipitação. Na Figura 2C (janeiro) nota-se um ciclo bem definido do FCS com máximos de $32 \mathrm{~W} \mathrm{~m}^{-2}$ ocorrendo entre 13 e 14 h e mínimos entre 4 e $5 \mathrm{~h}$ com valores de até $-12 \mathrm{~W} \mathrm{~m}^{-2}$. É oportuno salientar que no mês em questão choveu apenas em três dias (3, 7 e 27) perfazendo o total mensal de 7,66 $\mathrm{mm}$ de um total de $50 \mathrm{~mm}$ esperado pela normal climatológica; outro detalhe é que os valores de FCS se tornam positivos somente a partir das $9 \mathrm{~h}$ (aproximadamente 3,5 h depois do nascer do Sol) e negativos entre 18 e $20 \mathrm{~h}$, o que confirma o retardo da difusão de calor no solo do manguezal, cuja difusidade térmica foi de $3,58 \times 10^{-5} \mathrm{~m}^{2} \mathrm{~s}^{-1}$, valor este muito maior que o encontrado por Harrison \& Phizacklea (1987) em um estuário na Escócia $\left(0,41 \times 10^{-6} \mathrm{~m}^{2} \mathrm{~s}^{-1}\right)$ usando o mesmo método de estimativa; na ocasião, eles afirmaram que o calor distribuído entre a "lama” e a água era puramente resultado de um processo difusivo molecular.

Quando se analisa o mês de junho (Figura 3), correspondente à época chuvosa, observa-se nitidamente que o FCS do mangue é bastante influenciado pela precipitação visto que a mesma provoca alteração no padrão diário e diminui o ciclo do FCS, já que é possível notar que em alguns dias o FCS foi sempre negativo (dias 13 e 14; 18 e 19); sabe-se, contudo que, normalmente, a temperatura da água proveniente da chuva é menor que a temperatura da superfície, fazendo com que a mesma seja suprida pelo fluxo ascendente de calor no solo, devido não só à já relatada diminuição de aquecimento solar da superfície por conta da sua atenuação pelo dossel mas, também, em virtude das perdas radiativas que transportam calor da superfície do solo para a atmosfera; com isto, o transporte de calor no solo ocorre das camadas mais profundas em direção à superfície; então, este resultado é uma combinação da precipitação e da atenuação

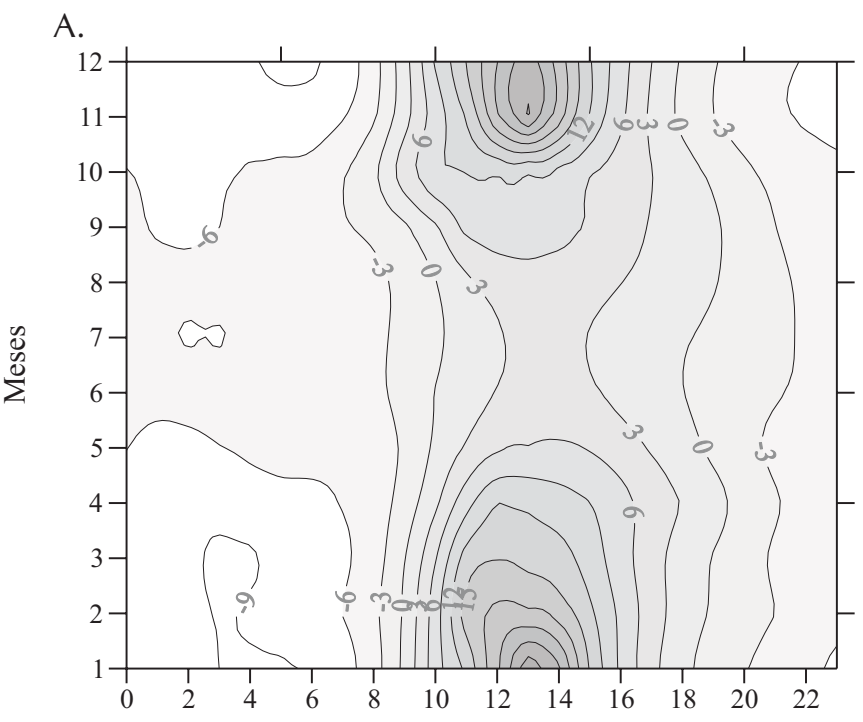

B.
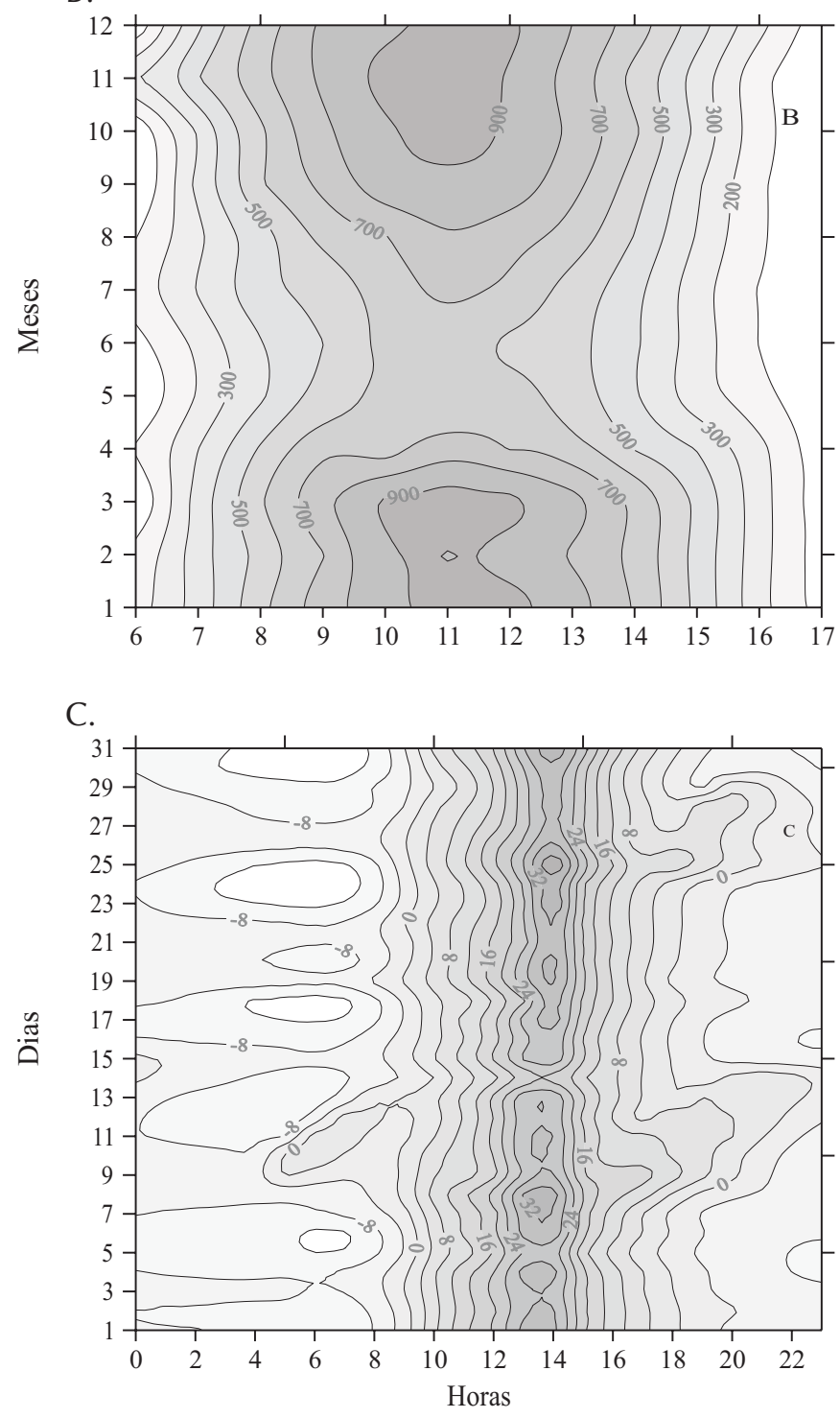

Figura 2. Variação média horária mensal do fluxo de calor no solo (A), em $W \mathrm{~m}^{-2}$ na profundidade de $10 \mathrm{~cm}$, da radiação solar global $(B)\left(W \mathrm{~m}^{-2}\right)$ e do fluxo de calor no solo (C) ( $\left.\mathrm{W} \mathrm{m}^{-2}\right)$ na profundidade de $10 \mathrm{~cm}$ no mês de Janeiro no manguezal 


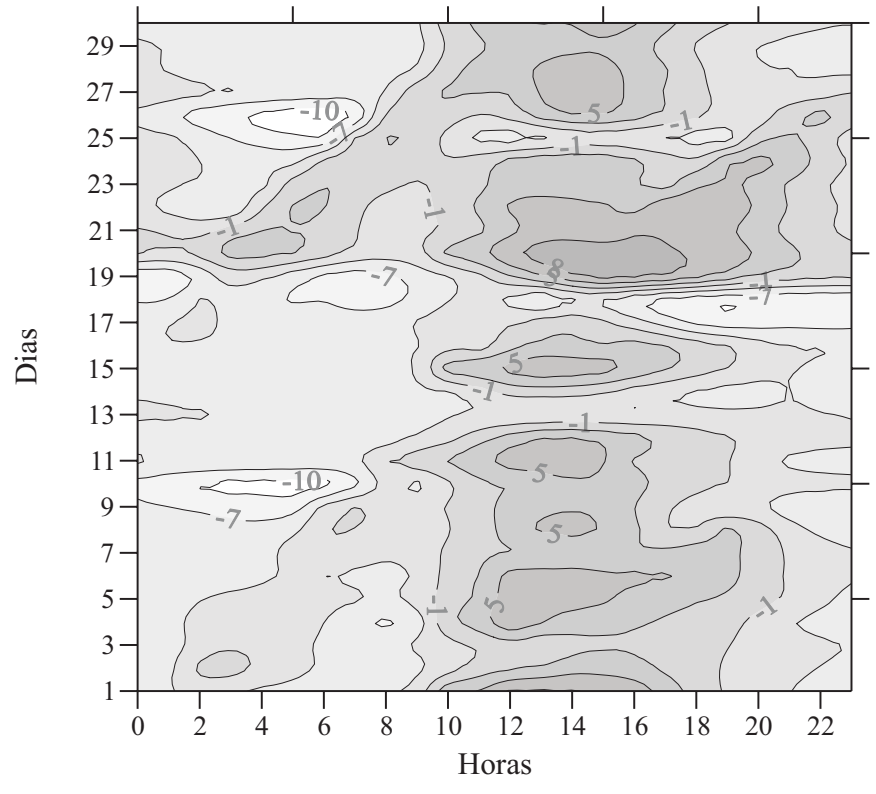

Figura 3. Variação média horária mensal do fluxo de calor no solo $\left(\mathrm{W} \mathrm{m}^{-2}\right)$ na profundidade de $10 \mathrm{~cm}$ no mês de junho, em um manguezal tropical

da radiação solar global (Rg) pelo dossel, conforme já relatado; o fato vem confirmar, obviamente em conjunto com a precipitação, que o aquecimento superficial nesta época do ano é menos elevado, o que ocasiona amplitudes médias diárias de FCS menores $\left(18 \mathrm{~W} \mathrm{~m}^{-2}\right)$.

É interessante se destacar, aqui, a dinâmica térmica do solo, uma vez que o FCS ainda pode sofrer influência do ciclo da maré vez que, em princípio, a entrada da água proveniente da maré parece ter impacto insignificante no aumento ou extensão do FCS mas isto depende muito da grandeza da maré, conforme detectado por Moura et al. (2006) quando identificaram a influência da mesma sobre a temperatura do solo do manguezal.

Examinando-se mais atentamente as Figuras 2C e 3, verifica-se que o ciclo diário do FCS pode ser influenciado pelo ciclo da maré, mais exatamente quando a amplitude da maré é máxima, o que proporciona um fluxo máximo ou mínimo de água, fazendo com que a superfície do manguezal seja diretamente exposta à atmosfera; desta forma, o solo se aquece mais intensamente em função da radiação solar, que incide diretamente, e das características físicas do solo, uma vez que o mesmo apresenta 84\% (Tabela 1) de areia (fina e grossa) em sua composição, fazendo com que o calor seja mais rapidamente transferido para as camadas mais profundas já que, conforme Jesus (2004) a condutividade térmica média da areia seca é de $0,33 \mathrm{~W} \mathrm{~m}^{-1}{ }^{\circ} \mathrm{C}^{-1} \mathrm{e}$ de $1,13 \mathrm{~W} \mathrm{~m}^{-1}{ }^{\circ} \mathrm{C}^{-1}$ a da areia úmida, apesar de Arias (1995) mostrar diminuição da condutividade térmica em solos saturados com ar e água com o aumento de temperatura.

Antes do ocaso solar o solo do manguezal começa a resfriar por emissão de radiação mas não o consegue, em sua total capacidade, pois logo em seguida a maré volta a subir, forçando a água ainda aquecida dos canais a penetrar no manguezal. Como se sabe, o poder conservativo de calor da água é maior que do solo, isto é, a água aquece e resfria muito mais lentamente que o solo; consequentemente, pode manter seu calor por mais tempo. Como o FCS é o resultado preliminar da difusão molecular de calor mas é dependente das propriedades térmicas do meio e das condições meteorológicas ambientais (Harrison \& Phizacklea, 1987), isto faz com que o FCS se eleve pelo calor adquirido da água, conforme demonstrado detalhadamente na Figura 4, na qual se pode notar as subidas e descidas do FCS em função da maré, o que demanda mais tempo para que o FCS seja negativo.

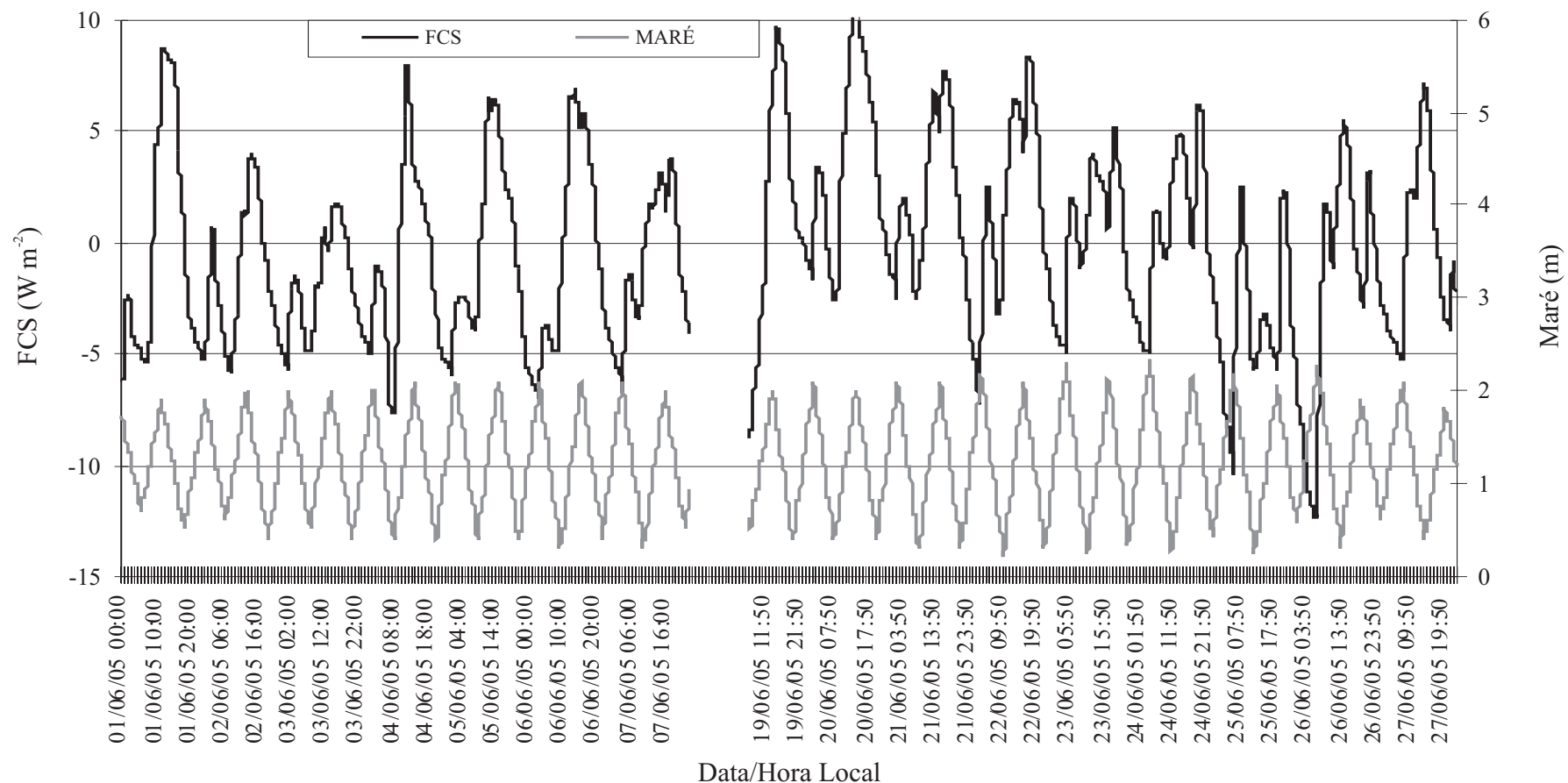

Figura 4. Variação instantânea do fluxo de calor no solo (FCS), em W m²- em função da maré (m) nos períodos de 01 a 07 de junho e 19 a 27 de junho, no manguezal 
Esses fenômenos podem ser contemplados nos períodos de 08 a 15 e 24 a 30 de janeiro, na Figura 2C, oportunidade em que o FCS só se torna negativo por volta das $22 \mathrm{~h}$. O mesmo fenômeno também pode ser visualizado na Figura 3, mais nitidamente no período de 19 a 26 de junho. O fenômeno da "ascendência” do valor de FCS por influência da maré também pode ser constatado quando a maré máxima ocorre 2-3 h antes do nascer do sol (Figura 4), simplesmente pelo fato de que o solo está em franco processo de resfriamento e, como a água está mais aquecida em função da sua inércia térmica, então o calor da água vai sendo conduzido e armazenado no interior do solo.

\section{CONCLUSÕES}

1. O estudo revelou que a variação sazonal do fluxo de calor no solo (FCS) é uma função da radiação solar, precipitação e maré.

2. A amplitude média diária na época chuvosa $\left(9 \mathrm{~W} \mathrm{~m}^{-2}\right)$ decresceu em relação à época seca $\left(36 \mathrm{~W} \mathrm{~m}^{-2}\right)$ em claro sinal de que o fluxo de calor no solo depende diretamente da radiação solar incidente e da precipitação.

3. Quando a amplitude da maré é máxima sua influência sobre o FCS independe do horário que pode ser pelo fato de expor o solo diretamente à ação direta da radiação solar ou pelo afluxo das águas provenientes dos canais com temperatura superior ou inferior à do manguezal.

\section{AGRADECIMENTOS}

Os autores gostariam de expressar seu agradecimento à FAPEAL (Fundação de Amparo à Pesquisa do Estado de Alagoas) pelo financiamento para a realização deste estudo, através do Projeto 20030929343-3.

\section{LITERATURA CITADA}

Arias, M. A. V. Thermal conductivity measurements of porous media. Austin: University of Texas. 1995. 75p. Dissertação Mestrado

Cabús, R. C. Tropical daylighting: Predicting sky types and interior illuminance in north-east Brazil. Reino Unido: Universidade de Sheffield. 2002. 15p. PhD Thesis

Calado, T. C. dos S.; Sousa, E. C. de. Crustáceos do complexo Estuarino-Lagunar Mundaú/Manguaba. 1.ed. Maceió: FAPEAL. 2003. 116p.

Clough, B. F. Primary productivity and growth of mangrove forests. In: Robertson, A. I.; Alongi, D. M. (ed.). Tropical mangrove ecosystems. Coastal and estuarine studies \#41. Washington: American Geophysical Union, 1992. p.225-250.

Day Jr., J. W.; Coronado-Molina, C.; Vera-Herrera, F. R.; Twilley, R.; Rivera-Monroy, V. H.; Alvarez-Guillen, H.; Day, R.; Conner, W. A. 7 year record of above-ground net primary production in a southeastern Mexican mangrove forest. Aquatic Botany, v.55, p.39-60, 1996.
DHN - Diretoria de Hidrografia e Navegação. http:// www.mar.mil.br/dhn. 07 Nov. 2007

Firme, L. P. Caracterização físico-químico de solos de mangue e sua avaliação de sua contaminação por esgotos domésticos via traçadores fecais. Piracicaba: ESALQ. 2003. 70p. Dissertação Mestrado

Harrison, S. J.; Phizacklea, A. P. Vertical temperature gradients in muddy intertidal sediments in the Forth estuary, Scotland. Limnology and Oceanography, v.32, p.954-963, 1987.

IMA - Instituto de Meio Ambiente/Governo de Alagoas. Zoneamento ambiental da APA de Santa Rita e reserva ecológica do Saco da Pedra. Maceió: Convênio IMA-GTZ. 1993. 50p.

Jesus, C. L. C. Determinação da condutividade térmica de rochas sedimentares a partir de perfilagem elétrica de poços. Salvador: UFBA. 2004. 62p. Dissertação Mestrado

Kimball, B. A.; Jackson, R. D.; Nakayama, F. S.; Idso, S. B.; Reginato, R. J. Soil-heat flux determination: Temperature gradient method with computed thermal conductivities. Soil Science Society America Journal, v.40, p.25-28, 1976.

Lamberti, A. Contribuição ao conhecimento da ecologia das plantas do manguezal de Itanhaém. Boletim de Botânica, v.23, n.317, p.1-27, 1969.

Liebethal, C.; Huwe, B.; Foken, T. Sensitivity analysis for two ground heat flux calculation approaches. Agricultural and Forest Meteorology, v.132, p.253-262, 2005.

Lima, I. F. Maceió, a cidade restinga: Uma contribuição ao estudo geomorfológico do litoral alagoano. 2.ed. Maceió: EDUFAL. 1990. 255p.

Lugo, A. E.; Brown, S.; Brinson, M. Forested wetlands in freshwater and salt-water environments. Limnology and Oceanography, v.33, p.894-909, 1988.

Moura, M. A. L.; Querino, C. A. S.; Lyra, R. F. F.; Nascimento Filho, M. F.; Mariano, G. L. Alguns aspectos da interação da maré e precipitação na variação sazonal da temperatura do solo em um manguezal tropical. In: Congresso Brasileiro de Meteorologia, 14, 2006, Florianópolis. Anais... Florianópolis: SBMET, 2006. CD Rom.

Querino, C. A. S. Avaliação da radiação solar em ecossistema de manguezal tropical em Alagoas, Brasil. Maceió: UFAL. 2006. 97p. Dissertação Mestrado

Ribeiro, J. B. M.; Rocha, E. J. P.; Ferreira, M. A. V.; Oliveira, P. J.; Mattos, A. Característica do balanço de energia no manguezal de Bragança-PA e alterações do fluxo de calor no solo em função do desmatamento. Geografia (Rio Claro), v.32, n.3, p.683-698, 2007.

Schaeffer-Novelli, Y. Manguezal: Ecossistema entre a terra e o mar. 1.ed. São Paulo: Caribbean Ecological Research. 1995. 64p.

Schaeffer-Novelli, Y. Avaliação e ações prioritárias para conservação da biodiversidade da zona costeira e marinha. Brasília: MMA/SBF. 2002. 72p.

Sediyama, G. C.; Prates, J. E. O microclima: Possibilidade de modificaçâo. Informe Agropecuário, v.12, n.138, p.36-42, 1986.

Silans, A. M. B. P.; Monteny, B. A.; Lhomme, J. P. Apparent soil thermal diffusivity, a case study: HAPEX-Sahel experiment. Agricultural and Forest Meteorology, v.81, p.201-216, 1996.

R. Bras. Eng. Agríc. Ambiental, v.14, n.3, p.296-302, 2010. 
Teixeira, R. L.; Sá, H. S. Abundância de macrocrustáceos decápodas nas áreas rasas do complexo lagunar Mundaú/Manguaba, AL. Revista Brasileira de Biologia, v.58, p.393-404, 1998.

Vance, D. J.; Haywood, M. D. E.; Staples, D. J. Use of a mangrove estuary as a nursery area by postlarval and juvenile banana prawns, Penaeus merguiensis de Man, in northern Australia. Estuarine, Coastal and Shelf Science, v.31, p.689-701, 1990.
Vanucci, M. Os manguezais e nós: Uma síntese de percepções. São Paulo: EDUSP, Instituto Oceanográfico, 1999. 233p.

Verhoef, A.; Hurk, B. J. J. M. van Den; Jacobs, A. F. G.; Heusinkveld, B. G. Thermal soil properties for vineyard (EFEDAI) and savanna (HAPEX-Sahel) sites. Agricultural and Forest Meteorology, v.78, p.1-18, 1996. 